\title{
Prediction of water temperature metrics using spatial modelling in the Eastern and Western Cape, South Africa
}

\author{
NA Rivers-Moore ${ }^{1 *}$, S Mantel ${ }^{2}$ and HF Dallas ${ }^{3}$ \\ ${ }^{1}$ School of Agricultural, Earth and Environmental Sciences, University of KwaZulu-Natal, P/Bag X01, Scottsville 3209, South Africa \\ IInstitute for Water Research, Rhodes University, PO Box 94, Grahamstown 6140, South Africa \\ ${ }^{3}$ Freshwater Research Unit, University of Cape Town, Private Bag X3, Rondebosch 7700, South Africa
}

\begin{abstract}
Key aspects of a river's temperature regime are described by magnitudes, timing and durations of thermal events, and frequencies of extreme exceedance events. To understand alterations to thermal regimes, it is necessary to describe thermal time series based on these statistics. Classification of sites based on their thermal metrics, and understanding of spatial patterns of these thermal statistics, provides a powerful approach for comparing study sites against reference sites. Water temperature regime dynamics should be viewed regionally, where regional divisions have an inherent underpinning by an understanding of natural thermal variability. The aim of this research was to link key water temperature metrics to readilymapped environmental surrogates, and to produce spatial images of temperature metrics: 37 temperature metrics were derived for 12 months of sub-daily water temperatures at 90 sites in the Eastern Cape and Western Cape provinces, South Africa. These metrics were correlated with 16 environmental variables. Correlations enabled development of multiple regression models which facilitated mapping of temperature metrics over the study area. This approach has the potential to be applied at a national scale as more thermal time series are collected nationally. It is argued that the appropriateness of management decisions in rivers can be improved by including guidelines for thermal metrics at a regional scale. Such maps could facilitate incorporation of a temperature component into management guidelines for water resources.
\end{abstract}

Keywords: classification, ecological Reserve, environmental surrogates, multiple regression modelling, water resources management, water temperatures

\section{Introduction}

Measured stream temperatures are final values resulting from a number of complex assimilated physical processes. These can be grouped into drivers (which operate beyond the boundaries of the stream, and control the rate at which heat and water are delivered to the stream system); insulators (which influence the rate of heat exchange with the atmosphere) and buffers (which store heat already in the system, and integrate the variation in flow and temperature over time) (Poole and Berman, 2001).

Water temperatures, together with flow regimes, are equally important 'master variables' in explaining differences in invertebrate community structure (Jackson et al., 2007; Poff and Zimmerman, 2010). The importance of water temperatures to aquatic biota has been well documented (Claska and Gilbert, 1998; Eaton, 1996; Elliott, 1994; Sullivan et al., 2000), with temperature being a key factor affecting the number and kinds of species in a stream (Vannote and Sweeney, 1980). Annual thermal variation allows closely-related species to be sequenced temporally, and thus avoid competition, while diel temperature change increases the potential number of species which can coexist, as each one will be exposed to an optimum temperature during the day (Vannote and Sweeney, 1980). The degree of predictability in a stream's water temperatures provides an indication of the degree of structure and functional predictability of invertebrate communities (Vannote and Sweeney, 1980).

\footnotetext{
* To whom all correspondence should be addressed.

욜 +27 72 199-1472; fax: +27 33 260-5818 e-mail: blackfly1@.vodamail.co.za

Received 14 December 2010; accepted in revised form 2 April 2012.
}

Changing the thermal regime of a river alters a primary component of the environment for which river organisms are adapted (Ward, 1985), and decreased values of ecological metrics typically mirror changes in temperature/flow metrics (Jackson et al., 2007; Poff and Zimmerman, 2010). In general, human activities tend to simplify the physical structure of aquatic systems, thereby eliminating natural buffers and insulators. Daily, seasonal and intra-annual temperature ranges all increase with the loss of temperature buffering and insulating processes, because maximum temperatures become higher and minimum temperatures become lower (Poole et al., 2001). Increased water temperatures have been associated with shifts from temperate to neotropical assemblages (Bogan and Lytle, 2007).

There has been a renewed interest recently in statistical analysis of water temperatures (e.g. Nelitz et al., 2007) and in the generation of temperature criteria for aquatic ecosystems. Mean daily water temperatures are inadequate on their own to be able to describe changes in river ecosystems, because such a metric fails to capture data on extreme events which lead to chronic/ acute ecosystem stress. Rather, it is helpful to think of stream temperatures in terms of a 'temperature regime', and to describe the regime based on its statistical characteristics. Temperature criteria typically have 3 key elements: (i) a threshold temperature that signals when adverse biological responses are likely to occur, (ii) temperature statistics within the amplitude of fluctuation (e.g. maximum, mean or minimum); and (iii) an averaging period that indexes the duration of exposure likely to trigger that response (Sullivan et al., 2000). To derive a meaningful biological measure for specific life-phase requirements, careful consideration must be given to both magnitude and duration of temperature, since these factors together have 
great effect on the risk that temperature poses to aquatic biota (Sullivan et al., 2000).

The mean, median, maximum, minimum and variance should all be used to describe a temperature regime within the amplitude of fluctuation for a given length of stream over a given period of time. Measures of the time and location at which mean, maximum and minimum temperatures occur are useful as well (Poole et al., 2001). In perennial streams, summer maximum temperatures play a dominant role in the distribution of species (Dunham et al., 2003). A temperature regime describes the distribution of the magnitude of stream temperature, the frequency with which a given temperature occurs, the time of day or year when a given temperature occurs, and the duration of time for which a stream is above or below a given temperature (Poole et al., 2001). Biologically, it is the magnitude, frequency, timing and duration of thermal events that affect aquatic biota by impacting on their life history cues and fecundity (Olden and Naiman, 2010). Changes in the timing of maximum and minimum temperatures can occur with or without associated changes in the magnitude of maximum, minimum and mean temperatures. Understanding the predictability or cyclical constancy of water temperatures, and how this changes with downstream distance, is an important predictive tool in relating biotic responses to abiotic change.

Averaging periods range from an instantaneous maximum, to a 7-day average, seasonal average and monthly average (Sullivan et al., 2000). Averaging approaches typically use a 7-day moving window, for example, the average of daily maximum temperature of 7 warmest consecutive days (ODEQ, 1995), or the average of daily mean temperatures of 7 warmest consecutive days (US EPA, 1977). A 7-day moving average of daily maximum water temperatures has been related to fish distributions in the Sabie River (Rivers-Moore et al., 2005) and blackfly outbreak probabilities (Rivers-Moore et al., 2008a)

For water temperature time-series data to be meaningfully used as a management tool in river systems requires, firstly, that sites can be classified into thermal groups based on a classification of their metrics. A temperature classification offers numerous advantages to conservation and water resource managers, because it provides the spatial tool through which management programmes can be applied uniformly to broad geographic regions (Hart and Campbell, 1994). For example, it becomes possible to predict the natural biota from a modified river by extrapolating from a similar but unmodified river (O'Keeffe et al., 1994). A good classification forms a necessary prerequisite to select 'representative' river systems, reference sites and monitoring programmes (Hart and Campbell, 1994), and forms a necessary basis from which to undertake ecological and condition assessments (Hart and Campbell, 1994).

While the criteria chosen for the classification are crucial to the utility of it, one classification will not satisfy all potential users (O'Keeffe et al., 1994).

Thermal regimes vary geographically in response to climate and catchment characteristics (geology, Strahler's stream order, topography, land cover) (Poff and Zimmerman, 2010). Given the general dearth of water temperature data in South Africa (Rivers-Moore et al., 2008b), it becomes necessary to use spatial surrogates which correlate with thermal metrics as a key to spatially map thermal metrics. Providing a spatial component to thermal metrics facilitates incorporation of thermal aspects into environmental flow management (Jackson et al., 2007; Olden and Naiman, 2010), and makes it possible to link modified sites to reference sites.



Figure 1

Map of loggers used in Western Cape and Eastern Cape provinces (Gridlines at $100000 \mathrm{~m}$ intervals, Projection Transverse Mercator; Spheroid WGS84; Io 23)

The aims of this research were to generate temperature metrics from sub-daily water temperature time series data to describe the magnitude, frequency, timing and duration of thermal events; to characterise and group sites using these metrics; to link these metrics to readily mapped environmental surrogates; and to spatially map selected metrics in the Eastern Cape and Western Cape provinces of South Africa. Mapping of these metrics could facilitate incorporation of a temperature component into improved management guidelines for water resources in South Africa.

\section{Methods}

\section{Source data and data screening}

Sub-daily water temperature data from a total of 90 sites in the Western Cape and Eastern Cape, representing 8 ecoregions (Kleynhans et al., 2005) and 7 river longitudinal zones (geomorphological classes) (Moolman, 2008), formed the core analyses basis for this study (Fig. 1). For the Eastern Cape, 1 year of hourly data for 2009 at 28 sites was analysed, and supplemented with 2-hourly data from 2008 at 15 sites in the Southern Cape (De Moor, 2010). For the Western Cape, 1 year of hourly data for 2009 was collected from 47 sites, including 16 sites with half-hourly data from the Table Mountain Aquifer region (City of Cape Town, 2009). Sites were separated into upper and lower river sites based on their longitudinal zone: upland $(70$ sites $)=$ mountain streams, transitional and upper foothill sites; lowland $(20$ sites $)=$ lower foothills, rejuvenated foothills, and lowland sites. The spatial distribution of sites was a trade-off between collecting data over as wide a range of river systems and longitudinal zones as possible, and at the same time providing data within individual river systems to describe change with downstream distance. Location of sites was not aimed at gaining representivity within catchments, and it is acknowledged that the spatial configuration of loggers could result in a degree of autocorrelation in time series at adjacent sites.

Data were screened for completeness of data records, where the criterion for best data was a full year's time series of hourly water temperatures where the logger had remained immersed for the full period of logging. Sites with data missing for 1 to 


\begin{tabular}{|c|c|c|}
\hline \multicolumn{3}{|c|}{$\begin{array}{c}\text { Table } 1 \\
\text { Temperature metrics for disaggregating thermal time series }\end{array}$} \\
\hline \multirow{4}{*}{\multicolumn{2}{|c|}{ Annual descriptive statistics }} & Mean + Std. Dev. of annual temperature \\
\hline & & \\
\hline & & \begin{tabular}{|l|} 
Predictability $^{\#}$ (Colwell, 1974) \\
\end{tabular} \\
\hline & & Mean + Std. Dev. of daily range \\
\hline Group 1 & Monthly magnitudes & Oct-Sept mean temperatures \\
\hline \multirow[t]{4}{*}{ Group 2} & \multirow{4}{*}{$\begin{array}{l}\text { Magnitude and duration of annual extreme water } \\
\text { temperature conditions }\end{array}$} & $1,3,7,30 \& 90$-day minima \\
\hline & & $1,3,7,30 \& 90$-day maxima \\
\hline & & Degree days (annual) \\
\hline & & $\begin{array}{l}\text { Mean daily minimum } \\
\text { Maximum diel range }\end{array}$ \\
\hline Group 3 & $\begin{array}{l}\text { Timing - Julian date of maximum and minimum } \\
\text { metrics (thermal triggers) }\end{array}$ & $\begin{array}{l}\text { Date of onset of longest exceedance of minimum threshold } \\
\text { Date of onset of longest exceedance of maximum threshold }\end{array}$ \\
\hline Group 4 & $\begin{array}{l}\text { Frequency and duration (successive days of event } \\
\text { above or below a threshold) }\end{array}$ & $\begin{array}{l}\text { Minimum temperature threshold }{ }^{1} \text { count and duration } \\
\text { Maximum temperature threshold }{ }^{2} \text { count and duration }\end{array}$ \\
\hline
\end{tabular}

\# Predictability was defined according to Colwell (1974), where temporal patterns are classified according to their state (class) at a point in time. The predictability of any periodic phenomenon is maximal when there is complete certainty with regard to state for a point in time. Class intervals are $2^{\circ} \mathrm{C}$, which is based on a standard deviation of water temperatures from a typical upland site.

$122^{\circ} \mathrm{C}$

2 Julian max temperature threshold was set based on the site's longitudinal zone along the river. A threshold of $18^{\circ} \mathrm{C}$ was used for mountain streams, transitional and upper foothill sites, while $25^{\circ} \mathrm{C}$ was used for lower foothills, rejuvenated foothills, and lowland sites.

2 days, or where the logger was known to have been out of water for a limited period and therefore recording air temperatures, were identified. At these sites, data were in-filled using averages of hourly data from 1 to 2 days preceding and succeeding the event. Generally, a maximum of 1-2 missing data periods per site were encountered and corrected for in the dataset. Sites with longer gaps $(\leq 1$ month) in the data were included in the analyses, resulting in not all months having data from the full complement of sites. This was unavoidable, and the purpose of keeping these sites in the analyses was to have the greatest spatial spread of sites possible. Sites where gaps were longer than this ( $>1$ month), such as when loggers had been exposed, were excluded from the analyses. It is acknowledged that data gaps could have an averaging effect on data analysis, although these influences would be small given that hourly data is converted to daily data which were analysed over the period of a single year, and a 2-day infill as a maximum criterion represents $0.5 \%$ of the time series for a site.

\section{Calculation of temperature metrics}

The development of families of temperature metrics is an extension of previous research in which 20 sites in 4 river systems in South Africa were classified using ordinations based on 16 temperature metrics (Rivers-Moore et al., 2008b). Sub-daily data for a full year (January to December 2009) were converted to daily data (mean, minimum, maximum and range). From these data, 37 metrics were calculated to describe water temperatures with respect to magnitude of water temperatures, frequency, timing and duration of thermal events (Richter et al., 1996, 1997; Olden and Naiman, 2010; Rivers-Moore et al., 2010) (Table 1).

Data were standardised/normalised for comparison of variables measured on different scales. Cluster analysis was then undertaken to define thermal groups (Clarke and Gorley, 2001) using the group averaging agglomerative option and Euclidean distance as the distance measure. The standardised/normalised data were then analysed by group using principal component analysis, and to determine which temperature metrics had the greatest influence on site groupings (McCune and Mefford, 1999; Clarke and Gorley, 2001).

Because of the short period of data analyses, concerns regarding the inter-annual stability (or relevance) of the metrics were addressed through comparisons of metrics for corresponding periods in a successive year (1 January - 31 December 2010) at 22 selected sites which represented all thermal groups identified in the classification above for the Eastern Cape and Western Cape provinces. Metrics which did not show high $(>0.8)$ degrees of correlation with other temperature metrics were compared for statistically significant differences using 2 approaches. In the first approach, metrics between 2009 and 2010 were compared using paired Student's $t$-tests for dependent samples $(p<0.05)$ (StatSoft, 2003). For the second approach, site pairs using a Principal Components Analysis (McCune and Mefford, 1999) (centred correlation matrix) were compared. Absolute differences between co-ordinates of sites for paired years for Axis 1 and Axis 2 were calculated, and mean deviances from zero difference were tested using a Student's $t$-test.

\section{Spatial modelling}

Sixteen environmental surrogates were selected because of published correlations with water temperatures (for example, Vannote and Sweeney, 1980; Ward, 1985; Sullivan et al., 1990; Rivers-Moore et al., 2008b) (Table 2). All 37 temperature metrics were correlated with environmental variables, to reduce the number of site characteristics for analyses and highlight environmental variables most important for spatial modelling. Principal component analysis (PCA), together with correlation matrices, was conducted to determine which variables were important predictors of groupings of sites (Primer 5 for Windows 2002; Clarke and Gorley, 2001), using the approach of Rivers-Moore and Goodman (2010). These correlative relationships were further explored using simple linear regression models for selected temperature metrics versus percentage downstream distance of river, latitude, altitude and stream order. 


\begin{tabular}{|l|l|}
\hline \multicolumn{2}{|c|}{$\begin{array}{c}\text { Table 2 } \\
\text { Environmental variables selected for correlation with temperature metrics for Eastern Cape and } \\
\text { Western Cape logger sites (Label abbreviations in bold refer to Fig. 4) }\end{array}$} \\
\hline Environmental variable and description & Source \\
\hline Distance from stream source to logger site (1:500 000 scale) & DWAF (2005) \\
\hline Total downstream distance (total downstream distance from stream source to mouth) (Dist) & DWAF (2005) \\
\hline$\%$ downstream distance $(\% \boldsymbol{D D})$ & DWAF (2005) \\
\hline Aspect, measured as degrees downstream & N/A \\
\hline Latitude $(\boldsymbol{L a t})$ & N/A \\
\hline Longitude $(\boldsymbol{L o n g})$ & N/A \\
\hline Ecoregion & Kleynhans et al. (2005) \\
\hline Longitudinal zone $($ Zone) $)$ & Moolman (2006, 2008) \\
\hline Stream order $($ Strahler's stream orders) & DWAF (2005) \\
\hline Altitude (m above mean sea level) & N/A \\
\hline Geology & Vegter (1995) \\
\hline Secondary catchment area $\left(\mathrm{km}{ }^{2}\right)$ & Schulze (2006) \\
\hline Secondary catchment perimeter $(\mathrm{km})$ & Schulze (2006) \\
\hline Secondary catchment number & Schulze (2006) \\
\hline River length per secondary catchment (1:500 000 scale) $)$ & N/A \\
\hline Drainage density (river length/catchment area) & N/A \\
\hline
\end{tabular}

\begin{tabular}{|l|c|c|c|}
\hline \multicolumn{4}{|c|}{$\begin{array}{c}\text { Table } 3 \\
\text { Range of temperature metrics for } \mathbf{9 0} \text { sites collected during the study in the Eastern } \\
\text { Cape and Western Cape. Note that, while } \mathbf{9 0} \text { sites made up the total sample size, not } \\
\text { all sites had data for all } \\
\text { months of } \mathbf{2 0 0 9} \text { (i.e. } \boldsymbol{n} \mathbf{9 0} \text { in certain cases). }\end{array}$} \\
\hline Metric & $\mathbf{N}$ & Minimum & Maximum \\
\hline Mean annual temp. (MAT) & 90 & 12.13 & 24.96 \\
\hline Std. dev. of MAT & 90 & 0.84 & 5.01 \\
\hline CV\% of MAT & 90 & 0.05 & 0.28 \\
\hline Annual range (mean) & 90 & 0.94 & 10.15 \\
\hline Std. dev. of annual range & 90 & 0.41 & 4.19 \\
\hline CV\% of annual range & 90 & 0.21 & 0.97 \\
\hline October mean temperature & 48 & 14.42 & 20.71 \\
\hline November mean temperature & 52 & 14.93 & 22.72 \\
\hline December mean temperature & 87 & 14.32 & 26.13 \\
\hline January mean temperature & 86 & 11.94 & 25.90 \\
\hline February mean temperature & 88 & 11.63 & 26.37 \\
\hline March mean temperature & 84 & 11.55 & 25.68 \\
\hline April mean temperature & 82 & 11.83 & 22.24 \\
\hline May mean temperature & 57 & 10.25 & 19.46 \\
\hline June mean temperature & 43 & 8.20 & 18.55 \\
\hline July mean temperature & 18 & 9.04 & 17.66 \\
\hline August mean temperature & 18 & 10.13 & 17.44 \\
\hline September mean temperature & 20 & 10.42 & 18.28 \\
\hline
\end{tabular}

As a first step in the spatial modelling process, stepwise forward multiple linear regression models were developed for selected water temperature metrics and 5 environmental variables (latitude, altitude, ecoregion, geology and stream order). The thermal metrics were chosen based on their degree of correlation with other temperature metrics, and the degree to which they could be represented spatially.

Next, raster images for the independent environmental variables were derived. Of particular note, a national grid image of altitude was used from Schulze (2006). Stream order per quaternary catchment was calculated by assigning the highest stream order to occur in each quaternary catchment, based on input images of rivers (DWAF, 2005; Schulze, 2006). A latitude image was created from a quarter-degree point coverage which was interpolated using a raster-based geographical information system (GIS). The grid images were manipulated (using regression coefficients and algebraic procedures according to the multiple linear regression models) in a grid-based GIS (Clark Labs, 2009). To verify the reliability of the spatial images of selected metrics, modelled values were compared with values from the 22 sites previously mentioned. Metrics from 1 year's temperature data for 2010 were correlated with modelled values for the same 22 sites derived from the images.

\section{Results}

\section{Water temperature metrics and classification of sites}

The range of the temperature values for the calculated metrics for the 90 sites (Table 3 ) showed large variation in recorded 


\begin{tabular}{|c|c|c|c|c|}
\hline \multicolumn{5}{|c|}{$\begin{array}{c}\text { Table } 4 \\
\text { Sites from the Eastern Cape and Western Cape provinces for which temperature } \\
\text { metrics were compared from 2009 and 2010. Metrics which were significantly different } \\
\text { between years (Student's } t \text {-test, } 21 \text { d.f., } p<0.05 \text { ) are indicated by * (Further explanations } \\
\text { for metrics are provided in Tables } 1,6) \text {. }\end{array}$} \\
\hline \multirow[t]{2}{*}{ Metric } & \multicolumn{2}{|c|}{2009} & \multicolumn{2}{|c|}{2010} \\
\hline & Mean & SD & Mean & SD \\
\hline Annual mean & 16.47 & 1.78 & 16.51 & 1.72 \\
\hline Annual CV\%* & 23.27 & 6.30 & 24.58 & 4.92 \\
\hline Predictability $^{*}$ & 0.65 & 0.08 & 0.61 & 0.07 \\
\hline Annual minimum (mean) & 15.14 & 1.86 & 15.06 & 1.80 \\
\hline Annual maximum (mean) & 18.11 & 1.96 & 18.31 & 1.94 \\
\hline June* mean & 12.08 & 2.41 & 11.32 & 1.88 \\
\hline July mean & 11.25 & 2.37 & 11.15 & 1.80 \\
\hline Min-7 & 8.78 & 2.89 & 8.16 & 2.20 \\
\hline Max-7* & 25.15 & 2.83 & 26.49 & 3.21 \\
\hline Daily range (maximum) & 8.59 & 3.78 & 9.47 & 4.64 \\
\hline Minimum temperature count & 96 & 58 & 101 & 53 \\
\hline Maximum temperature count & 114 & 82 & 118 & 78 \\
\hline Julian minimum & 151 & 54 & 155 & 40 \\
\hline Julian maximum & 20 & 58 & 21 & 51 \\
\hline
\end{tabular}

values for the 2009 data. Data were not available for all months at all sites, and this is acknowledged as potentially skewing some of the statistics on the metrics. Of the 14 metrics compared between years, 10 were not statistically different, while metrics reflecting variability (annual coefficient of variation and Colwell's (1974) predictability), together with June means and extreme maxima (maximum of the 7-day moving average of daily maxima), were significantly different between years (Table 4). For the PCA, sites between years generally showed small positional shifts in metric space (Fig. 2), although differences between paired years for Axes 1 and 2 were not statistically different from zero (Student's $t$-test, $\mathrm{p}<0.05 ; 21$ d.f.) (Table 5). Cumulative variance explained by PC Axes 1 and 2 was 47.81 and $72.28 \%$ (eigenvectors not shown).

Based on the cluster analyses, 13 thermal groups were derived, and 2 of these groups were excluded from the PCA because their membership was too small (i.e. $n<2$ ) (Fig. 3). Many of the thermal metrics were highly correlated, and a PCA based on 14 metrics adequately described sites in PC space (Table 6). Thermal groups were fairly discrete in ordination space, with little overlap between groups. Two group pairs (12 and 13; 9 and 10) shared the same parent group, which accounted for the overlap between groups in PC space. Thermal groups could be represented along gradients of selected thermal metrics, including water temperature means and coefficients of variations. Groups could be characterised based on how cool versus warm they were (PC1) and on their

Figure 2

PCA for paired years of data for 22 sites in the

Eastern Cape and Western Cape provinces. Site codes are provided in Table 5, while prefixes 1 and 2 refer to 2009 and 2010 respectively. level of predictability (PC2). Group 7 was an 'average' group, while Group 4 was the coolest group and Groups 12 and 13 the warmest. The last-mentioned group consisted largely of sites along the Great Fish River, in the warmer Eastern Cape region, in a river system with regulated flows and in which temperatures were consequently not highly unpredictable. Group 5 had the most predictable thermal regimes. The coolest water groups (3 and 4) were largely upland river sites.

\section{Spatial modelling}

Of the 90 sites, downstream distance for 20 sites could not be calculated as they were on tributaries that were not indicated on the 1:500 000 rivers coverage. The analyses were thus conducted using site characteristics and metrics based on 1 year's data for 70 sites. A correlation matrix of

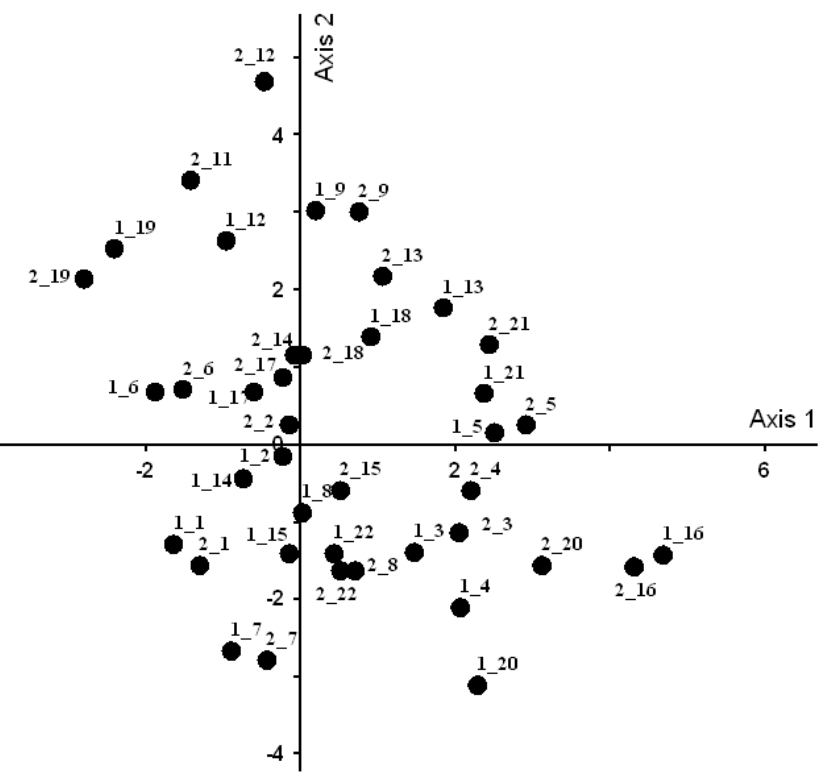




\section{Table 5}

Differences in metric coordinate space for sites between years for Axes 1 and 2 of a PCA. Site codes are based on the primary and secondary catchment code (e.g. E1) plus a portion of the river and site names, and site details are provided in Dallas and Rivers-Moore (2012).

\begin{tabular}{|l|c|c|c|c|c|}
\hline Site & Site No. & Thermal Group & Long. zone & Axis1 & Axis2 \\
\hline E1Dwar-Kraka & 1 & 5 & Upland & -0.33 & 0.26 \\
\hline E1Rate-Beave & 2 & 7 & Upland & -0.10 & -0.41 \\
\hline G2Eers-Jonke & 3 & 10 & Upland & -0.59 & -0.27 \\
\hline H1Elan-Tunne & 4 & 8 & Upland & -0.14 & -1.50 \\
\hline H1Witr-Monum & 5 & 10 & Upland & -0.41 & -0.11 \\
\hline H4Bree-Lecha & 6 & 13 & Lowland & -0.36 & -0.03 \\
\hline K4Dwars-Channel & 7 & 5 & Lowland & -0.45 & 0.12 \\
\hline K3Keur-Monta & 8 & 9 & Upland & -0.69 & 0.75 \\
\hline K6Keur-Outen2 & 9 & 11 & Upland & -0.56 & 0.01 \\
\hline L8Bav-Res1 & 10 & 1 & Lowland & -1.49 & -0.77 \\
\hline L8Bav-Res2 & 11 & 1 & Lowland & -5.58 & -4.94 \\
\hline M1Eland-Cyph & 12 & 12 & Lowland & -0.49 & -2.06 \\
\hline N1Gats-Aasvoe & 13 & 11 & Upland & 0.78 & -0.40 \\
\hline P4Blou-Res & 14 & 7 & Lowland & -0.68 & -1.59 \\
\hline Q1Gbrak-Dekeur & 15 & 6 & Lowland & -0.68 & -0.80 \\
\hline Q4Tark-Oak & 16 & 3 & Upland & 0.38 & 0.15 \\
\hline Q8Kvis-Cookh & 17 & 13 & Lowland & -0.38 & -0.19 \\
\hline Q9Balf-Wfall & 18 & 2 & Upland & 0.88 & 0.23 \\
\hline Q9Fish-Trum & 19 & 12 & Lowland & 0.39 & 0.40 \\
\hline T4RSE3-Channel & 20 & 4 & Upland & -0.83 & -1.54 \\
\hline W7-1Drakenstein & 21 & 3 & Upland & -0.06 & -0.62 \\
\hline W7-4Kasteelskloof & 22 & 9 & Upland & -0.08 & 0.23 \\
\hline Mean & & & & -0.52 & -0.59 \\
\hline Std. Dev. & & & & 1.25 & 1.22 \\
\hline
\end{tabular}


Figure 3

Principal component analysis of thermal groups ( $P C$ axes 1-2) (showing thermal metrics which were best correlated with thermal groups) of water temperature logger sites in the Eastern Cape and Western Cape

\section{Table 6}

PCA of 14 thermal metrics to describe variation in 90 sites in the Eastern Cape and Western Cape provinces

\begin{tabular}{|l|c|c|}
\hline PA Axes & $\mathbf{1}$ & $\mathbf{2}$ \\
\hline \%. Cumulative variance & 37.30 & 67.57 \\
\hline Variables & & \\
\hline Annual mean & -0.407 & 0.137 \\
\hline Annual CV\% & 0.226 & 0.271 \\
\hline Predictability & -0.096 & -0.385 \\
\hline Annual minimum (mean) & -0.405 & -0.027 \\
\hline Annual maximum (mean) & -0.333 & 0.304 \\
\hline Daily range (mean annual) & 0.010 & 0.422 \\
\hline Mean (June \& July) & -0.420 & -0.004 \\
\hline Min-7 & -0.316 & -0.253 \\
\hline Max-7 & \\
\hline Daily range (maximum) & -0.185 & 0.415 \\
\hline Minimum temperature count $^{\$}$ & -0.037 & 0.377 \\
\hline Maximum temperature count $^{\$}$ & 0.413 & 0.090 \\
\hline Julian minimum $^{\#}$ & 0.062 & 0.310 \\
\hline Julian maximum $^{\#}$ & -0.115 & 0.029 \\
\hline
\end{tabular}

"7-day moving average of daily minimum and maximum temperatures

${ }^{s}$ Number of times within a year that the minimum/maximum temperature threshold was exceeded

"Julian date on which longest period of successive days of temperature threshold exceedance (maximum and minimum) begins.

the 16 site characteristics showed that 3 of them (secondary catchment, catchment perimeter $(\mathrm{km})$ and total river length per secondary catchment) were highly correlated (correlation coefficient $>0.8$ ) with other characteristics and could 




Figure 4

Correlation biplots of sites (top) and main environmental variables characterising sites (bottom) for the first 2 axes of the PCA. Axes 1 and 2 cumulatively explained 50.64 and $76.32 \%$ of the data variation. See Table 2 for explanation of labels.

be excluded from further analyses. These parameters were also not significantly correlated with the first 2 axes of a PCA conducted using all site characteristics (Fig. 4). From the biplot, the environmental variables contributing most to explaining site variance were altitude and stream order. Stream orders were correlated with downstream distances, and are less intensive to calculate than downstream distances. Correlation matrices between selected environmental and temperature metrics showed that different environmental predictors applied to upper versus lower sites. Furthermore, while catchment area, downstream distance and aspect were not significantly correlated with any of the temperature metrics, the most universal environmental surrogate for temperature metrics was altitude.

Selected thermal metrics (annual mean daily temperature, annual maximum temperature and mean annual daily range) were regressed against individual environmental variables, to enable generalisations in trends from the data. The annual means of mean daily temperatures increased with increasing downstream distance and stream order, and decreased with increasing altitude and distance from the equator (Eqs. (1a) to (1d)). The best correlations achieved were between mean daily water temperatures and stream order, followed by per cent downstream distance of stream channel. No correlations were found between the same environmental variables and maximum temperatures and mean daily range.

$$
\begin{aligned}
& M A T=15.554+0.033(\% D D) \quad R^{2}=0.32 ; p<0.0001 \quad(1 \mathrm{a}) \\
& \text { MAT }=17.022-0.002(\text { Alt }) \quad R^{2}=0.13 ; p=0.0005 \\
& M A T=14.670+0.994(S O) \quad R^{2}=0.44 ; p<0.0001 \\
& M A T=39.327+0.687(\text { Lat }) \quad R^{2}=0.09 ; p=0.004 \\
& \text { where: } \\
& M A T \text { is annual mean daily temperature } \\
& \% D D \text { is percentage downstream of total river length } \\
& \text { Lat and Alt are latitude and altitude (-ve decimal degrees), } \\
& \text { respectively } \\
& S O \text { is Strahler stream order }
\end{aligned}
$$

Five environmental variables (latitude, altitude, ecoregion, geology and stream order) were selected as predictor variables for estimating thermal metrics using multiple linear regression models. The predictor variables were chosen based on their level of correlation with the thermal metrics, and the ease with which they could be spatially mapped. Latitude and/or altitude were ubiquitous predictor variables in all 7 models developed, while ecoregion and geology were included in only one model each.

Multiple linear regression models $(n=90, p<0.0001)$ for mean annual temperature at 3 different levels of parsimony (Eq. (2a) - all terms: $R^{2}=0.67$; Eq. (2b) - geology and ecoregions excluded: $R^{2}=0.64$; and Eq. $(2 \mathrm{c})$ - only latitude and altitude included: $R^{2}=0.49$ including and excluding stream order, respectively), standard deviation of mean daily water temperature $\left(R^{2}=0.29, p<0.0001\right.$; Eq. (3)), coefficient of variation of mean daily water temperature $\left(R^{2}=0.23, p<0.0001\right.$; Eq. (4)) and 7-day moving average for minimum $\left(R^{2}=0.45\right.$; $p<0.0001$; Eq. (5)) and maximum temperature $\left(R^{2}=0.12\right.$, $p<0.0001$; Eq. (6)) are provided. Mean annual water temperature (Fig. 5), $M A T_{S D}, M A T_{C V}, M i n_{7}$ and Max , were spatially mapped, and reclassified into suitable class intervals. Verification using data was derived using data from 2010 for at least 1 site from the 13 thermal groups identified $(n=22)$. Results showed mixed correlative values, ranging from $R^{2}=0.50$ for mean annual water temperatures (Fig. 6; $p=0.0003)$, to 0.45 for $\operatorname{Min}_{7}(p=0.0009)$ and 0.14 for annual coefficient of variation $(p=0.1)$.

$$
\begin{aligned}
M A T= & 54.34+1.10(\text { Lat })+0.57(\text { SO })-0.003(\text { Alt }) \\
& -0.19(\text { Geo }) \\
M A T= & 49.05+0.98(\text { Lat })+0.69(\text { SO })-0.003(\text { Alt }) \\
M A T= & 73.90+1.67(\text { Lat })-0.004(\text { Alt }) \\
M A T_{S D}= & 16.68+0.39(\text { Lat })+0.16(\text { SO }) \\
M A T_{C V}= & 21.28+0.007(\text { Alt }) \\
\operatorname{Min}_{7}= & 8.01+0.43(\text { SO })-0.003(\text { Alt })+0.28(\text { Ecoregion }) \\
\operatorname{Max}_{7}= & 79.52+1.62(\text { Lat })
\end{aligned}
$$

where:

Lat, Alt, Geo, SO refer to latitude (-ve values), altitude (m a.m.s.1.), geology and stream order respectively. 




Figure 5

Mean annual water temperatures for Eastern Cape and Western Cape provinces of South Africa, reclassified into temperature class intervals of $2^{\circ} \mathrm{C}$.

\section{Discussion}

A river's thermal regime is a key, yet poorly acknowledged, component of environmental flows (Olden and Naiman, 2010). While environmental flows have been increasingly established and researched in South African rivers since the 1980s (King et al., 2003), water temperature research in South Africa has only started to gain more prominence in the past decade (see, for example Rivers-Moore et al., 2005). With the focus on river heterogeneity signatures gathering momentum in the aquatic conservation field of South Africa, it is important to bear in mind that, while rivers may be classified as having excellent habitat based on their flow and geomorphology signatures, they may be thermally polluted (Harris and Silveira 1995).

In this study it was demonstrated that sub-daily temperature data from sites covering a range of ecoregions and longitudinal zones can be successfully disaggregated into metrics that describe the magnitude, frequency, timing and duration of thermal events. These metrics permit measurement of departure from reference conditions, whereby a reference condition describes a (statistical) distribution rather than a single absolute value, i.e. temporal and spatial variability that is inherent in any measure chosen to represent the natural state of environmental systems (Stoddard et al., 2006).

Practical examples on the use of temperature metrics include applications in research in aquatic disease vectors and freshwater conservation efforts. In the former case, better prediction of mosquito larval survival is achieved through diurnal water temperature dynamics (minimum and maximum) rather than mean daily water temperatures in understanding mosquito larval dynamics (Paaijmans et al., 2008). In the latter case, Mohseni et al. (1999) demonstrated, based on projections of air temperature increases, that most streams in the United States will have maximum temperature increases by 2050 in spring, with considerable negative impacts on cold-water stenothermic fish species particularly.

Thermal metrics and thresholds only begin to form a holistic management approach once incorporated into a spatial framework. Correlation with environmental variables which can be spatially represented provides the 'Rosetta Stone' to spatially represent water temperature metrics. Mixed success was achieved in spatially mapping individual metrics in the

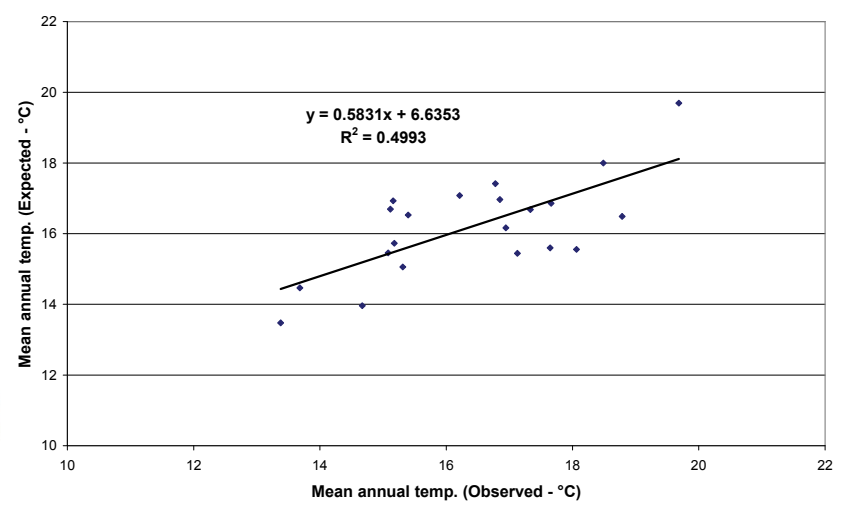

Figure 6

Correlation between observed and modelled mean annual temperatures for the 22 sites listed in Table 5 and based on data for 2010

Eastern and Western Cape. Given the complex interactions between drivers, buffers and insulators at each site, this is not surprising, and similar trends in modelling metrics for lotic systems have been observed elsewhere. Wenger et al. (2010) were able to successfully model several ecologically relevant aspects of the hydrological regime, although predictions for sites with strong groundwater influence were not as good as for surface-water-driven systems. The range of success varied in correlations between predicted and observed data for various metrics, with mean annual flows being predicted with good accuracy (Wenger et al., 2010).

Uncertainties and mixed success in spatially modelling thermal metrics are to be expected, given that establishing causative relationships between changes in water temperature signatures and natural cycles is difficult, because of the compounding effects of anthropogenic influence (Nelitz et al., 2007). Human impacts change the amount (magnitude) or timing of the heat load delivered to the watercourse or by modifying the flow regime (Poole and Berman, 2001). Additionally, streams differ in their sensitivity to modifications, and the relative contribution of heat inputs changes seasonally, i.e. the impacts of modified drivers and insulators are not constant during the year (Webb et al., 2008). Any reduction in the buffer efficiency leads to larger swings in cyclical response patterns, resulting in higher maxima and lower minima (daily and seasonal) (Poole and Berman, 2001), which may not be accounted for in predictive models. Model performance may have been improved by incorporating local-scale insulators (shading), but this presents problems because such local variables are difficult to represent spatially at a regional scale. Future research could focus on sensitivity analyses for the multiple regression models to estimate different thermal metrics.

Given the lack of comprehensive regional and long-term data, a pragmatic approach for mapping thermal metrics is to follow an atlas-based approach (sensu Schulze, 2006), whereby a series of images for different temperature metrics is produced. Images could be reclassified into classes, for example by defining class intervals as mean $\pm n$ standard deviations. Given longer-term collection of water temperatures at a national scale, such expanded maps could be used to indicate baseline reference conditions and associated natural ranges of variability. A second approach is to divide South Africa into thermal regions, using, for example, mean annual temperatures as the classifier. Whichever approach is adopted retains 
the utility value of these maps, which will facilitate a regional approach in deriving temperature guidelines for rivers in South Africa.

To reduce the chances of mismanaging the condition of a river requires taking cognisance of the full spectrum of flows together with thermal regimes, including their temporal and spatial variability (King et al., 2003). To date, no proposals have been developed for the water temperature component of the ecological Reserve, a legislated framework for securing water quality and quantity for the environment as a legitimate user of water (SA National Water Act; RSA, 1998), although the importance of water temperatures in maintaining river systems is now recognised. While there is legislative provision for a river's ecological Reserve which includes flows and, theoretically, temperatures, inclusion of water temperatures into the Reserve still requires considerable research.

For wiser decision-making on behalf of aquatic ecosystems, it is necessary to be able to describe expected responses of river thermal regimes to anthropogenic influences (Poole and Berman, 2001). Direct and indirect impacts on water temperatures occur through reductions in flows (groundwater and surface water) and catchment land use (indirect), all of which affect a river's natural thermal regime (Olden and Naiman, 2010). Since the primary source of energy for warming streams is the sun, increasing or decreasing the amount of energy reaching a stream causes increases in maximum temperatures (Brown and Krygier, 1970) or decreases in minimum temperatures. For example, the forest canopy (shading) modifies the amount of solar radiation influencing stream temperatures: Johnson (2003) showed that, for conditions at midday in summer, an open reach under full sun experienced a net energy gain of $580 \mathrm{Wm}^{-2}$, but a reach under full shade had a net loss of $149 \mathrm{Wm}^{-2}$. Surface-subsurface exchanges (typically expressed as groundwater inflow rate: $\mathrm{m}^{3} \mathrm{~s}^{-1} \mathrm{~km}^{-2}$ ) of water have also been recognised as significantly influencing the heat budgets of small streams, because groundwater inflows add to heat storage capacity, and moderate annual variation.

Detecting responses of thermal regimes to anthropogenic influences requires establishing long-term monitoring of water temperatures based on the temperature groups and spatial map, and analyses to detect trend(s) over time. Observed trends (departure from baseline conditions) should act as triggers of management intervention through exceedance of defendable thresholds. Such an approach would require monitoring at selected sites, and annual updates of the temperature metrics to identify trends (Esterby, 1996). In monitoring networks, data are collected at several locations over time, primarily to detect trends but also spatial patterns. One year of data, which shows stability over a 2-year period, is not enough to start drawing conclusions on thermal changes in rivers. What is required is ongoing monitoring of water temperatures at key sites, to detect possible trends.

The establishment of baseline water temperature monitoring sites at a national level, on a long-term basis, will be a step towards achieving thermal metrics maps at a national scale. With long-term time series, ongoing research would be able to focus on more extensive validation and verification of maps, and ultimately work towards a national classification of water temperature regions. A significant benefit of such datasets, if collected in conjunction with ecological data, is to measure thermal trends with time, including potential climate change impacts, and link this to observed changes on aquatic community patterns.

\section{Acknowledgements}

We gratefully acknowledge the Water Research Commission for funding this research. Ferdy de Moor (Albany Museum, Grahamstown) and TMGA - Ecohydrological Monitoring Alliance (TMGA-EMA) (GEOSS, Freshwater Consulting Group, Coastec) are thanked for provision of some of the temperature data. Craig Morris (ARC/ UKZN) is thanked for assistance with multivariate analyses. Comments from 2 anonymous reviewers on an earlier manuscript draft are gratefully acknowledged.

\section{References}

BOGAN MT and LYTLE DA (2007) Seasonal flow variation allows "time-sharing" by disparate aquatic insect communities. Freshwater Biol. 52 290-304.

BROWN GW and KRYGIER JT (1970) Effects of clearcutting on stream temperature. Water Resour. Res. 6 1133-1139.

CITY OF CAPE TOWN (2009) Table Mountain Group Aquifer Exploratory Phase Ecological and Hydro(geo)logical Monitoring Project. Preliminary Data Analysis Report - Volume A. Prepared by the Table Mountain Group Aquifer - Ecohydrological Monitoring Alliance (GEOSS, Freshwater Consulting Group, Coastec and the Soil Doctor).

CLARK LABS (2009) Idrisi Taiga v. 16.02. Clark University, Worcester MA. URL: http://www.clarklabs.org.

CLARKE KR and GORLEY RN (2001) PRIMER v5: User Manual Tutorial. PRIMER-E Ltd., Plymouth, UK.

CLASKA ME and GILBERT JJ (1998) The effect of temperature on the response of Daphnia to toxic cyanobacteria. Freshwater Biol. 39 221-232

COLWELL RK (1974) Predictability, constancy, and contingency of periodic phenomena. Ecology 55 1148-1153.

DALLAS HF and RIVERS-MOORE NA (2012) Water Temperatures and the Ecological Reserve. WRC Report, Water Research Commission, Pretoria, South Africa.

DE MOOR FC (2010) Personal communication, 29 March 2010. Dr FC de Moor, Albany Museum and Department of Zoology and Entomology, Rhodes University, Somerset Street, Grahamstown, 6140 , South Africa.

DWAF (DEPARTMENT OF WATER AFFAIRS AND FORESTRY, SOUTH AFRICA) (2005) RQS River coverage - 1: 500000. Institute for Water Quality Studies, Private Bag X313, Pretoria, 0001. URL: http://www.dwa.gov.za/iwqs/gis_data/RHPdata.asp (Accessed 28 August 2010).

DUNHAM J, SCHROETER R and RIEMAN B (2003) Influence of maximum water temperature on occurrence of Lahontan Cutthroat trout within streams. N. Am. J. Fish. Manage. 23 1042-1049.

EATON JG and SCHELLER RM (1996) Effects of climate on fish thermal habitat in streams of the United States. Limnol. Oceanogr. 41 1109-1115.

ELLIOTT JM (1994) Quantitative Ecology and the Brown Trout. Oxford University Press, Oxford.

ESTERBY SR (1996) Review of methods for the detection and estimation of trends with emphasis on water quality applications. Hydrol. Proc. 10 127-149.

HARRIS JH and SILVEIRA R (1999) Large-scale assessments of river health using an Index of Biotic Integrity with low diversity fish communities. Freshwater Biol. 41 235-252.

HARRIS NM, GURNELL AM, HANNAH DM and PETTS GE (2000) Classification of river regimes: a context for hydroecology. Hydrol. Proc. 14 2831-2848.

HART BT and CAMPBELL IC (1994) Ecological classification scheme for Australia. In: Uys MC (ed.). Classification of rivers, and environmental health indicators. Proceedings of a joint South African/ Australian workshop, February 7-14 1994, Cape Town, South Africa. WRC Report No. TT 63/94. Water Research Commission, Pretoria, South Africa. 
JACKSON HM, GIBBINS CN and SOULSBY C (2007) Role of discharge and temperature variation in determining invertebrate community structure in a regulated river. River Res. Appl. 23 651-669.

JOHNSON SL (2003) Stream temperature: scaling of observations and issues for modelling. Hydrol. Proc. 17 497-499.

KING J, BROWN C and SABET H (2003) A scenario-based holistic approach to environmental flow assessments for rivers. River Res. Appl. 19 619-639.

KLEYNHANS CJ, THIRION C and MOOLMAN J (2005) A Level I river ecoregion classification system for South Africa, Lesotho and Swaziland. Report No. N/0000/00/REQ0104. Resource Quality Services, Department of Water Affairs and Forestry, Pretoria.

McCUNE B and MEFFORD MJ (1999) Multivariate analysis of ecological data v. 4.17. MJM Software, Gleneden Beach, Oregon.

MOHSENI O, ERICKSON TR and STEFAN HG (1999) Sensitivity of stream temperatures in the United States to air temperatures projected under a global warming scenario. Water Resour. Res. 35 3723-3733.

MOOLMAN J (2006) Slope classification of southern African rivers. URL: http://www.dwaf.gov.za/iwqs/gis data/RHPdata.htm (Accessed 27 August 2010)

MOOLMAN J (2008) River long profiles aid in ecological planning. PositionIT $2008 \mathrm{Jan} / \mathrm{Feb}$ 43-47.

NELITZ MA, MACISAAC EA and PETERMAN RM (2007) A science-based approach for identifying temperature-sensitive streams for rainbow trout. N. Am. J. Fish. Manage. 27 405-424.

O'KEEFFE JH, KING J and EEKHOUT S (1994) The characteristics and purposes of river classification. In: Uys MC (ed.) Classification of rivers, and environmental health indicators. Proceedings of a Joint South African/Australian Workshop, February 7-14 1994, Cape Town, South Africa. WRC Report No. TT 63/94. Water Research Commission, Pretoria, South Africa.

OLDEN JD and NAIMAN RJ (2010) Incorporating thermal regimes into environmental flows assessments: modifying dam operations to restore freshwater ecosystem integrity. Freshwater Biol. 55 86-107.

ODEQ (OREGON DEPARTMENT OF ENVIRONMENTAL QUALITY) (1995) Water quality standards review. Department of Environmental Quality Standards \& Assessment Section, Oregon Department of Environmental Quality, Portland, Oregon.

PAAIJMANS KP, JACOBS AFG, TAKKEN W, HEUSINKVELD BG, GITHEKO AK, DICKE M and HOLTSLAG AAM (2008) Observations and model estimates of diurnal water temperature dynamics in mosquito breeding sites in western Kenya. Hydrol. Proc. 22 4789-4801.

POFF NL and ZIMMERMAN JKH (2010) Ecological responses to altered flow regimes: a literature review to inform the science and management of environmental flows. Freshwater Biol. 55 194-205.

POOLE GC and BERMAN CH (2001) Pathways of human influence on water temperature dynamics in stream channels. Environ. Manage. 27 787-802.

POOLE G, RISLEY J and HICKS M (2001) Spatial and temporal patterns of stream temperature (revised). Issue paper 3. United States Environmental Protection Agency. EPA-910-D-01-003.

RSA (REPUBLIC OF SOUTH AFRICA) (1998) National Water Act. Act No. 36 of 1998. Pretoria, South Africa.

RICHTER BD, BAUMGARTNER JV, POWELL J and BRAUN DP (1996) A method for assessing hydrologic alteration within ecosystems. Conserv. Biol. 10 1163-1174.

RICHTER BD, BAUMGARTNER JV, WIGINGTON R and BRAUN DP (1997) How much water does a river need? Freshwater Biol. 37 231-249.

RICHTER BD (2009) Re-thinking environmental flows: From allocations and reserves to sustainability boundaries. River Res. Appl. DOI: 10.1002/rra.1320.

RIVERS-MOORE NA and GOODMAN PS (2010) River and wetland classifications for freshwater conservation planning in KwaZuluNatal, South Africa. Afr. J. Aquat. Sci. 35 61-72.

RIVERS-MOORE NA, HUGHES DA and DE MOOR FC (2008a) A model to predict outbreak periods of the pest blackfly Simulium chutteri Lewis (Simuliidae, Diptera) in the Great Fish River, Eastern Cape province, South Africa. River Res. Appl. 24 132-147.

RIVERS-MOORE NA, HUGHES DA, MANTEL S and HILL TR (2008b) First steps in the development of a water temperature model framework for refining the ecological Reserve in South African rivers. Water SA 34 (5) 1-12.

RIVERS-MOORE NA and JEWITT GPW (2007) Adaptive management and water temperature variability within South African rivers: What are the management options? J. Environ. Manage. 82 39-50.

RIVERS-MOORE NA, JEWITT GPW and WEEKS DC (2005) Derivation of quantitative management objectives for annual instream water temperatures in the Sabie River using a biological index. Water SA 31 473-481.

SCHULZE RE (ed.) (2006) South African Atlas of Climatology and Agrohydrology. WRC Report No. 1489/1/06. Water Research Commission, Pretoria, South Africa.

STATSOFT, INC. (2003) STATISTICA (data analysis software system), Version 6. URL: www.statsoft.com.

STODDARD JL, LARSEN DP, HAWKINS CP, JOHNSON RK and NORRIS RH (2006) Setting expectations for the ecological condition of streams: The concept of reference condition. Ecol. Appl. 16 1267-1276.

SULLIVAN K, TOOLEY J, CALDWELL JE and KNUDSEN P (1990) Evaluation of prediction models and characterisation of stream temperature regimes in Washington. Timber/Fish/Wildlife Rep. No. TFW-WQ3-90-006. Washington Dept. Nat. Resources, Olympia, Washington. 224 pp.

SULLIVAN K, MARTIN DJ, CARDWELL RD, TOLL JE and DUKE $S$ (2000) An analysis of the effects of temperature on salmonids of the Pacific Northwest with implications for selecting temperature criteria. Sustainable Ecosystems Institute, Portland, Oregon. URL: http://www.sei.org/downloads/reports/salmon2000.pdf (Accessed 10 September 2010).

US EPA (1977) Temperature criteria for freshwater fish: protocol and procedures. Ecological Research Series. U.S. Environmental Protection Agency Office of Research and Development, Environmental Research Laboratory, Duluth, Minnesota. EPA600/3-77-061. $130 \mathrm{pp}$

VANNOTE RL and SWEENEY BW (1980) Geographic analysis of thermal equilibria: A conceptual model for evaluating the effect of natural and modified thermal regimes on aquatic insect communities. Am. Nat. 115 667-695.

VEGTER JR (1995) Geology map of South Africa with simplified lithostratigraphy for geohydrological use. (Simplified lithostratigraphy digitised by A Havenga, Council for Geosciences, 1994). WRC Report No. TT 74/95. Water Research Commission, Pretoria, South Africa.

WARD JV (1985) Thermal characteristics of running waters. Hydrobiologia 125 31-46.

WEBB BW, HANNAH DM, MOORE RD, BROWN LE and NOBILIS $\mathrm{F}$ (2008) Recent advances in stream and river temperature research. Hydrol. Proc. 22 902-918.

WENGER SJ, LUCE CH, HAMLET AF, ISAAK DJ and NEVILLE HM (2010) Macroscale hydrologic modelling of ecologically relevant flow metrics. Water Resour. Res. 46 WO9513. doi:10.1029/2009WR008839. 